\title{
Procurement 4.0: How industrial customers transform procurement processes to capitalize on digital servitization
}

\author{
David Sjödin ${ }^{1}$, Anmar Kamalaldin ${ }^{1}$, Vinit Parida ${ }^{1}$, Nazrul Islam²,* \\ ${ }^{1}$ Entrepreneurship and Innovation, Luleå University of Technology, Sweden \\ 2,* Department of Science Innovation Technology and Entrepreneurship, University of Exeter Business \\ School, UK
}

\begin{abstract}
The rapid development of digital technologies can revolutionize industrial companies' operations through the procurement and application of digital solutions following a logic of digital servitization. However, industrial customers must refine their internal processes to exploit the potential of digital servitization. In this transition, the procurement organization is pivotal in orchestrating relationships between its internal functions and suppliers ecosystems. Yet, traditional procurement processes are poorly suited to the evaluation and procurement of digital servitization offerings, hampering value co-creation between suppliers and customers. The purpose of this study is to investigate how procurement process models can be adapted to address the opportunities and challenges of digital servitization for industrial customers. The investigation is based on a case-study design, drawing on data collected through in-depth interviews with informants from eleven leading customers and eight global suppliers. Based on the data analysis following the Gioia methodology, we describe key challenges with the traditional approach and identify novel procurement practices to capture value from digitalization. The study's key contribution is to propose a process model for Procurement 4.0, highlighting four phases: 1) mapping digital opportunities, 2) selecting digitalization partners, 3) co-developing digital solution contracts, and 4) promoting continuous digital innovation. Furthermore, we define three overarching principles for procurement 4.0: a) nurture digital ecosystem generativity, b) orchestrate cross-functional integration, and c) leverage supplier capabilities through agile co-creation.
\end{abstract}


Managerial relevance statement: The rapid development of digital technologies can revolutionize industrial companies' operations through the procurement and application and of digital solutions following a logic of digital servitization. However, industrial customers must refine their internal processes to exploit the potential of digital servitization. This study investigates how procurement process models can be adapted to address the opportunities and challenges of digital servitization. The study highlights three key industrial customer challenges related to procuring digital solutions: evaluating value of digital solutions, prioritizing digital investment across organizational silos, and incentivizing supplier-driven digital innovation. The study's key contribution is to propose a process model for Procurement 4.0, highlighting four phases: 1) mapping digital opportunities, 2) selecting digitalization partners, 3) co-developing digital solution contracts, and 4) promoting continuous digital innovation. We pinpoint the key activities and key questions for each phase. In addition, we define three overarching principles for procurement 4.0: a) nurture digital ecosystem generativity, b) orchestrate cross-functional integration, and c) leverage supplier capabilities through agile co-creation. In doing so, we offer managers a new procurement logic and a basis for designing a procurement process to source digital solutions.

Keywords: Industry 4.0, Procurement 4.0, digitalization, digital transformation, digital servitization, digital solutions, advanced services, business model innovation 


\section{Introduction}

"Digitalization is a transformative force for our industry, and we realize that we cannot do it alone. We need to find better ways of working together with our suppliers to drive innovation in the selection, design, and implementation of new types of digitalization-enabled offerings. This is a key challenge for procurement, to facilitate this collaboration and to find ways of strengthening our competitiveness through supplier contributions." (Chief procurement officer of a mining company)

Digitalization is a fundamental disruptive force of the fourth industrial revolution (Industry 4.0) that is revolutionizing the way business is conducted in industrial value chains [1]-[3]. In this new age, industry is becoming increasingly "smart" by using the Internet of Things (IoT), intensive data exchange, and predictive analytics [4]. However, the definition of digitalization extends beyond technological applications. Specifically, digitalization is "the use of digital technologies to innovate a business model and provide new revenue streams and value-producing opportunities in industrial ecosystems" [5] (p. 6). While this transformation is often discussed from the supplier side in terms of business model innovation through digitally enabled products and services, the shift is equally important for their industrial customers who will use these offerings in their operations [6], [7]. The opportunities for industrial customers are vast; automation and optimization of processes can improve productivity and profitability by saving costs, accelerating production, and reducing errors, while providing environmental and safety advantages [5], [8]-[10]. To exploit these benefits, industrial customers must develop their capacity to acquire and seamlessly implement digital solutions such as fleet and site management and digital platforms. However, there is increasing evidence that large-scale digital solutions procurement by industrial customers is lagging in uptake, and existing examples often fail to realize their promised potential [11].

Thus, there is a need to further understand the challenges and to enable practices for the procurement of digital solutions [6]. In actual fact, it is increasingly clear that customers' 
procurement organizations are pivotal in orchestrating relationships between their internal functions and suppliers to ensure the creation and capture of value from digital offerings for themselves and their ecosystem of suppliers. However, this is not easy because procuring digital solutions requires a radical shift in customers' business and procurement logics. For example, digital solutions are more intangible and uncertain and may require alternate ways of designing, customizing, evaluating, and implementing such offerings within the supplier-customer relationship [12]. Indeed, many suppliers now offer complex digitally enabled product-servicesoftware systems targeting customer outcomes [13], [14]. Similarly, data-driven artificial intelligence solutions use operational data mining and analytics to suggest how best to optimize the use of not only single pieces of equipment but also entire fleets and production lines [5], [15]. These new trends in suppliers' offerings have been described as digital servitization, which refers to "[t]he transition to smart product-service-software systems that enable value creation and capture through monitoring, control, optimization, or autonomous function" [13]. Thus, fostering and exploiting digital service offerings require novel processes to procure new types of offering and to define how value is created, delivered, and captured by suppliers and customers [16], [17] in a way that departs from the standard procurement process [18].

We argue that traditional transactional procurement models act as an increasing constraint on procuring complex product-service-software systems [6], [13]. The alternative is to create new processes for procurement (Procurement 4.0) that can better support the agile, relational orientation needed to support the digital transformation of industrial companies. Building on emergent industrial discussions [19]-[21], we define Procurement 4.0 as a procurement approach to optimize supply chain efficiency, agility, and innovation through digitalization by focusing on strategically orchestrating relationships between various internal functions and suppliers ecosystems. This definition acknowledges the strategic role of procurement in digitalization by driving new value 
propositions from suppliers, meeting new business needs in internal functions and, more importantly, seeking the integration of data across internal functions and the industrial ecosystem [19]. However, several knowledge gaps remain concerning how industrial customer organizations can successfully transform their procurement practices to earn benefits from digital servitization.

First, there is a need to understand the challenges of procurement in digital servitization. Indeed, procuring digital solutions requires a radical shift in customers' business and procurement logics, shifting from a capital expenditures (CAPEX) model that focuses on procuring physical assets to an operating expenses (OPEX) model focusing on services and solutions [22], [23]. This necessitates a new relational perspective with key suppliers [6], [10], and the standard procurement process [24] is not well suited to these new types of offering [12]. Accordingly, many companies struggle with key procurement-related activities such as designing specifications, customizing solutions, and evaluating intangible digital solutions [11]. However, we currently lack insights into the new challenges related to implementing Procurement 4.0 practices. For example, many industrial customers struggle with evaluating and procuring digital solutions consisting not only of products or services but a guarantee that customers will achieve a certain outcome [11], [14]. Yet, we lack in-depth insights into the nature of these challenges relating to internal organizations, processes, and evaluation procedures. Thus, we seek to identify the key Procurement-4.0-related challenges facing digital servitization.

Second, there is a need to understand how industrial customers can structure their procurement processes to capitalize on digital servitization. Indeed, the transition to Procurement 4.0 is still in its infancy [25], and there are no clear guidelines on how industrial customers can transform their procurement processes to capture the value of digitalization. More specifically, industry and academia lack insights into the key phases and activities for the successful procurement of digital solutions. Indeed, most research has focused on the supplier perspective [5], [16], whereas current 
knowledge of how customers engage in procuring and implementing digital solutions remains in its nascent phase [6]. Consequently, there is a need to further investigate how traditional transaction-based procurement models [24], [26] can be adapted by firms to effectively orchestrate internal and supplier relationships so that digitalization creates and captures value for themselves and their ecosystem of suppliers.

In targeting these gaps in knowledge, the purpose of this study is to investigate how procurement process models can be adapted to address the opportunities and challenges of digital servitization for industrial customers. To fulfil this purpose, our study draws on the rich case-study data from eleven industrial customers and eight suppliers who are leading adopters of digital servitization in their industries.

Our findings offer several contributions to theory and practice in digital servitization and industrial procurement. First, we identify three key industrial customer challenges related to procuring digital innovations: evaluating value of digital solutions, prioritizing digital investment across organizational silos, and incentivizing supplier-driven digital innovation. Second, we further classify the blueprint of a revised four-phase process model for Procurement 4.0 in digital servitization, extending the traditional perspective [24]. We detail how the process unfolds over four phases: 1) mapping digital opportunities, 2) selecting digitalization partners, 3) co-developing digital solution contracts, and 4) promoting continuous digital innovation. Thus, we complement existing studies on the procurement process (e.g., [24]) and provide additional contingencies for digital servitization (e.g., [6], [27]). Third, we summarize our findings in an overall framework for Procurement 4.0, highlighting key overarching principles for capturing business value from digital innovation. In doing so, this study unpacks the underlying logics of procurement in the digital era, which focuses on nurturing digital ecosystem generativity, orchestrating cross-functional integration, and leveraging supplier capabilities through agile co-creation [6], [12]. Finally, the 
study explores the relational dynamics between the supplier and the customer as they realign their value-creation and value-capture perspectives. Here, we underscore the importance of an ecosystem perspective, with our findings strongly suggesting that digital servitization extends beyond standard dyadic relationships to increasingly involve the procurement of digital solutions enabled by an ecosystem of suppliers.

\section{Theoretical background}

Our theoretical background builds on literature detailing the evolving and increasingly strategic role of procurement function in firms, aiming to leverage supplier's expertise through procuring services rather than products. We further discuss the specific trends underlining the need for changing procurement processes to capitalize on digital servitization, as procuring digital solutions require a co-creation logic between customer and suppliers. In doing so, we describe the associated research gaps motivating us to conduct the present study.

\subsection{The evolving strategic role of procurement for digital servitization}

Since the 1990s, scholars have acknowledged that the role of procurement within firms has progressively evolved from an administrative to a strategic function [28]-[30]. With increasing competition and the need for specialization, recent decades have seen industrial firms engage in outsourcing activities and processes that fall outside their core competencies, enabling access to vital capabilities, technologies, and innovations from suppliers. This changed logic became increasingly evident as companies leveraged their suppliers' expertise by procuring advanced services rather than easily definable products. There is a clear need to empower procurement departments to drive efficiency and innovation from their suppliers ecosystems [31]. The increasing dependency on relationships with suppliers, and their growing strategic role [32], has emphasized the worth of a procurement function in fostering supplier-driven innovation [30]. 
Indeed, procurement is increasingly important for an organization and its partners to reduce costs and increase competitiveness and profitability [33]. For example, a well-functioning procurement unit can be instrumental in defining optimal stock levels at supplier and buyer warehouses, reducing overall capital commitment and price levels, leveraging innovation, or increasing supply chain intelligence through buyer-supplier relationships and alliances [24].

Indeed, procurement scholars continue to emphasize that the procurement of services is conspicuously different from the procurement of products (e.g., [34]-[36]). This is especially true of the digital servitization trend, where more and more suppliers move from either the provision of products to digital services or the integration of products, services, and software into hybrid solutions. However, procurement scholars recognize that insights are lacking on how organizations reshape the procurement function to efficiently procure digital solutions. A new procurement paradigm needs to be defined if industrial customers are to stay on the competitive edge; they must use their procurement function strategically and innovatively to leverage the potential of digital servitization [6], [20]. In essence, the task is to redefine procurement processes focusing on value rather than costs. Here, supplier ecosystems and their corresponding assets and capabilities need to be leveraged with particular emphasis on innovation, value, and strategy [20], [37]. This requires automating (or outsourcing) operational activities and focusing on strategic activities and initiatives [20], [38], [39]. Accordingly, there is a need to better understand Procurement 4.0 and what may likely follow in the next generation, as current research on this issue is still limited. There have been a number of attempts in conceptualizing the interaction of procurement and Industry 4.0 in literature and whitepapers, especially in the last five years, and different terms have been used. Table 1 shows examples of such conceptualizations, which we build on to comprehensively define Procurement 4.0 as a procurement approach to optimize supply chain efficiency, agility, and 
innovation through digitalization by focusing on strategically orchestrating relationships between

various internal functions and suppliers ecosystems.

Table 1. Examples of conceptualizations related to Procurement 4.0

\begin{tabular}{|l|l|l|}
\hline Authors and year & Term & Conceptualization \\
\hline $\begin{array}{l}\text { Geissbauer, ansth, and } \\
\text { Wetzstein, 2016 } \\
\text { [19] }\end{array}$ & $\begin{array}{l}\text { Procurement } \\
4.0\end{array}$ & $\begin{array}{l}\text { It involves the development of new value propositions and integration } \\
\text { of data across functions and value chains through a proactive use of data } \\
\text { and introduction of digital processes and tools. It requires the reshaping } \\
\text { of procurement capabilities to address the challenges and opportunities } \\
\text { of the digital revolution and meet new business needs. "Not only will } \\
\text { companies change what they buy... but importantly, they will also } \\
\text { change the ways in which they buy. The purchasing of services will } \\
\text { increase dramatically". }\end{array}$ \\
$\begin{array}{l}\text { Hughes and Ertel, } \\
2016 \text { [20] }\end{array}$ & $\begin{array}{l}\text { A new } \\
\text { procurement } \\
\text { paradigm }\end{array}$ & $\begin{array}{l}\text { The key task is to achieve maximum value through leveraging } \\
\text { supplier's assets, capacities, and capabilities in order to support the } \\
\text { firm's innovation and strategy. It requires procurement function to } \\
\text { automate operational activities to focus on strategic activities (cf. [37]). }\end{array}$ \\
\hline $\begin{array}{l}\text { Abidi, } \\
\text { Sommerer, and } \\
\text { Streif, 2018 [21] }\end{array}$ & $\begin{array}{l}\text { Digital } \\
\text { procurement }\end{array}$ & $\begin{array}{l}\text { A user-focused approach to digital transformation, which has } \\
\text { implications for how changes are designed, implemented, and renewed. } \\
\text { It requires procurement function to collaborate with business owners } \\
\text { and IT teams through an agile methodology. }\end{array}$ \\
\hline
\end{tabular}

\subsection{Why procurement processes need to change in digital servitization}

We argue that industrial customers attempting to capitalize on digital servtization need a substantially revised procurement process, following the logic of Procurement 4.0. Indeed, the proliferation of digital technologies points to radical changes at the core of business activity and a significant transformation of business models based on customer-supplier relationships and how they create, deliver, and capture value [6], [12]. These digital business models typically add more complex service and software elements to physical products to create customized customer solutions [13]. The shift to procuring these more complex types of digital solutions necessitates significant changes also in how procurement functions are organized.

The standard procurement process model is typically described in four linear stages: a) assignment specification, b) supplier selection, c) contract implementation, and d) outcome and 
evaluation [24], [26], [35]. While prior research acknowledges that the level of objectification varies at different stages and that complex services require a more dynamic perspective in procurement, many contingencies remain unclear. A revised procurement process for digital solutions needs to provide an organizational mechanism to coordinate and drive innovation and ecosystem cooperation and to integrate digital transformation internally. We argue that shifting to procurement of digital solutions demands change in the underlying principles of procurement for several reasons.

First, the output of digital solutions is often produced from the interaction between supplier and customer. This necessitates closer engagement with suppliers than simple transactional exchanges because the characteristics of digital solutions are such that they cannot be a priori stipulated in detail [6], [17]. Rather, they need to be co-created by buyers and suppliers in a more iterative and agile way through the procurement process [12], [35]. Accordingly, shifting to services and solutions results in a drive to create the trust and transparency needed to ensure long-term success in buyer-supplier relationships [6], [40], [41]. For example, suppliers can create higher value by being closer to customer's operations and designing solutions that address the specific pain points of the customer. More specifically, suppliers can use data from a fleet of equipment to identify areas for improvement in the customer's ongoing operational processes—for example, optimizing equipment and condition-based maintenance [42]. The suppliers ecosystem relationships that are required to deliver value are also changing, adding further complexity. For example, new governance challenges might arise when new stakeholders, such as cloud computing suppliers, become involved in the business and need to interact with existing machine suppliers [22]. Therefore, a vital need in the procurement process is the development of governance mechanisms and common information infrastructures to create transparency, traceability, and agility in using 
the increasing amount of information and data required to support the creation of digital solutions from suppliers ecosystems [6], [12].

Second, in digital servitization, the role of procurement as a downstream interface between internal and external processes needs to increasingly manage co-creation of cutting-edge digital solutions in innovative buyer-supplier relationships that promote a long-term perspective [6]. Accordingly, the shift to digital solutions often requires new competencies in evaluating offerings such as data analysis and software development, which surpass the existing procurement approaches and competences of industrial customers [23]. In addition, since the nature of these digital solutions is less clear, inputs from multiple organizational actors from development to operations are required to ensure appropriate specifications, shared value interpretation, and clear strategy for implementation [12]. Yet, many industrial companies have unclear organizational processes for procuring digital solutions and face organizational resistance and inertia in seeking to move beyond their legacy of procuring mechanical equipment [13].

Finally, companies face challenges in aligning incentives and contractual details in the procurement process. For example, digital solutions or product-service-software systems often mean moving from a capital expenditures (CAPEX) model, such as the traditional purchase of equipment with add-on repair and maintenance services, to an operating expenses (OPEX) model where the customer pays for an outcome-for instance, the amount of material processed by the equipment [22], [23]. While this shift in theory aligns incentives to a common goal, it also exposes the customer to significant uncertainty and risk, which it needs to manage because it is now dependent on the supplier. Some studies suggest that such supply risk can be reduced by focusing at an early stage on a more transparent flow of information, trust, and joint warning systems [6]. Yet, traditional procurement processes are not well adapted to deal with such contingencies. In 
contrast, recent research suggests that procurement holds a critical role in adjusting business models and contractual agreements to changing conditions over the life of the contract [12], [43].

To summarize, we argue that the research community's understanding of procurement of digital solutions remains limited. There is a strong need to further untangle the composition of processes that are more highly structured so that the procurement of increasingly intangible digital solutions can be aptly directed. Research on this remains limited, hence, we seek to address this gap in the literature by providing insights into how procurement process models can be adapted to address the opportunities and challenges of digital servitization for industrial customers.

\section{Methodology}

To understand how the next-generation Procurement 4.0 process for digital servitization is organized in industrial manufacturers, we adopted an inductive case-study design [44]. Case studies make it possible to mobilize multiple observations on complex relational and organizational dynamics [45], [46]. Case-study methodology is also particularly useful in developing inductive theory and fine-grained insights into a theoretically novel phenomenon [47], such as how procurement process models can be adapted to address the opportunities and challenges of digital servitization for industrial customers. The unit of analysis was the procurement process for digital solutions, and the focus was on the customer perspective. However, data was collected from a comprehensive sample involving both customers and suppliers in order to capture the relational perspective, following the suggestion of Tuli et al. [48] and Kamalaldin et al. [6] to collect data from both sides (i.e., both customer and supplier views). This approach facilitates a deeper understanding and contextual richness of the interactive dynamics within "the search, negotiation, contractual, and implementation phases" relevant to procurement in the digital servitization context [49] (p. 294). 


\subsection{Case selection and sampling strategy}

Our sample includes Swedish multinational business-to-business (B2B) companies that are active in the procurement (customers) or provision (suppliers) of digital solutions. To justify the generalizability of our findings, we followed the guidelines of Eisenhardt [50] in selecting cases from different industries and product categories. These firms represent diverse industries (e.g., mining, forestry, automotive, energy, telecom, manufacturing, and public transport), thus providing an opportunity to contrast various perspectives on the industrial procurement process. More specifically, three criteria guided our selection of cases. First, a key selection criterion was the ability of the companies to vividly describe concrete examples of procuring digital solutions and to provide in-depth information on the customer-supplier relationship and its key activities, supported by essential documentation and background information. Second, we sought to select more innovative (i.e., new to the firm) and complex examples of digital solutions with the aim of capturing cases that exemplified more significant shifts in the procurement process. Third, we selected companies where we had access to senior executives because of prior research cooperation. This made for rich data collection from a comprehensive sample of companies that spanned the perspectives of both customer (eleven companies) and supplier (eight companies) across diverse industries and, hence, enabled us to obtain an unbiased view. This broad range of companies and informants helped us to develop a holistic understanding of the procurement process, and the rich empirical base provided solid foundations to explore the novel phenomena of digital servitization and Procurement 4.0. Table 2 describes the key characteristics of the firms studied.

Table 2. Case companies description

\begin{tabular}{|l|l|l|l|l|}
\hline $\begin{array}{c}\text { Company } \\
\text { pseudonym }\end{array}$ & Industry & $\begin{array}{c}\text { Revenues (SEK } \\
\text { million) }\end{array}$ & $\begin{array}{c}\text { Number of } \\
\text { informants }\end{array}$ \\
\hline CUSTOMERS & Automotive & 500 & 1,000 & 4 \\
\hline Autocorp & Engines & 4,400 & 20,800 & 1 \\
\hline Enginecorp & Enges \\
\hline
\end{tabular}




\begin{tabular}{|l|l|l|l|l|}
\hline Energycorp & Energy and utilities & 700 & 3,000 & 3 \\
\hline Forestcorp & Forestry & 4,100 & 16,700 & 6 \\
\hline Ironcorp & Mining & 4,100 & 23,500 & 5 \\
\hline Minecorp & Mining & 5,700 & 49,500 & 12 \\
\hline Powercorp & Power generation & 4,200 & 16,000 & 3 \\
\hline Transcorp & Public transport & 7,500 & 6,500 & 1 \\
\hline Truckcorp & Automotive & 49,300 & 119,700 & 3 \\
\hline Pulpcorp & Paper packaging & 500 & 4,000 & 1 \\
\hline Zinkcorp & Mining & 370 & 2,350 & 3 \\
\hline SUPPLIERS & \multicolumn{5}{|l|}{} \\
\hline Constructcorp & Construction machinery & 14,000 & 4 \\
\hline Equipmentcorp & Construction machinery & 400 & 3,300 & 3 \\
\hline Harvestcorp & Forestry machinery & 600 & 2,600 & 3 \\
\hline Machinecorp & Industrial machinery & 2,400 & 11 \\
\hline Solutioncorp & Control and automation technology & 7,800 & 32,400 & 3 \\
\hline Connectcorp & Telecommunications equipment & 12,700 & 210,000 & 1 \\
\hline Autominecorp & High-tech and engineering & 41,000 & 100,000 & 4 \\
\hline Rockcorp & Construction and mining machinery & 13,000 & 31,000 & \\
\hline
\end{tabular}

\subsection{Data collection}

Data for the present study was gathered primarily through individual, in-depth interviews with participants, using a semi-structured interview guide. The unit of analysis was the procurement process for the digital service. Data on the procurement process were collected retrospectively and inductively, allowing for focused data gathering [51]. During the interviews, the respondents were instructed to reflect on the process of procuring digital solutions. For example, they were asked to consider questions such as: What are the challenges with procuring digital solutions? How does the process of identifying, selecting, designing, and implementing the digital solutions unfold? How are different organizational roles involved? What are challenges and best practices during specific phases? How did you select digital solutions to create the most value? How did you agree on the contractual details and profit sharing? The interview format was continuously updated to capture interesting themes as they emerged [52]. Departures from specific questions were permitted and the format of the interviews was adapted to allow the pursuit of interesting and particularly relevant facets as they emerged [50]. In seeking answers to these 
overarching questions, informants were encouraged to base their answers not only on the current procurement practices but also on their broader experience of procuring digital solutions. Thus, empirical comparisons were facilitated. The interviews ranged from one to three hours, with an average duration of 80 minutes.

In total, 75 interviews with informants from 19 companies were conducted (see Table 1 for details). Interviewees were identified by snowball sampling where key informants were asked to recommend people who played an active role in procurement in different phases. To capture a multifaceted view of the process, we interviewed informants from both customers and suppliers who had experience of exercising various functions and working in different phases. Examples of such positions included chief procurement officer, project manager, business development manager, operations managers, key account manager, and digitalization manager.

In order to avoid respondent bias leading to confusion on cause-effect relationships [51], we triangulated our data by applying multiple data collection techniques, including multiple interviews and a review of documents [53]. Document studies entailed reviewing company reports, agreements, and project documents (e.g., evaluations of key customer problems, internal assessments, PowerPoint presentations) in order to validate and to contextualize our respondents' views, thus enabling empirical triangulation. To increase reliability, enhance transparency, and create the possibility of replication, a case-study protocol was constructed along with a case-study database. The database included case-study notes, documents, and analysis.

\subsection{Data analysis}

Data analysis was based on a thematic analysis approach to identify relevant themes and patterns [54]. We followed the Gioa methodology, which allows researchers to identify patterns in a large and complex dataset [46], [55]. Moreover, it offers a means to identify links within analytical 
themes effectively and accurately. Through a series of iterations and comparisons, it is possible to identify themes and overarching dimensions so that an empirically grounded framework can be developed. In doing so, we followed a three-step approach similar to that described in the recent literature (e.g., [56], [57]).

The first step centered on an in-depth analysis of raw data (e.g., interview transcripts). This analysis focused on reading every interview several times and marking phrases and passages related to the overarching research question. By coding the common words, phrases, terms, and labels mentioned, it was possible to identify first-order categories of codes, which expressed the views of the informants. For example, informant statements such as: "We have to get more concrete insights on the operational challenges from our factory level staff to identify innovation opportunities" were coded under the label "seek insight from operational lead users to validate and refine demand specifications". This step was facilitated by MAXQDA software.

The second step of the analysis sought to discover links and patterns within the first-order categories. This iterative approach led to the formation of second-order themes that represent theoretically distinct concepts created by combining first-order categories. Our analysis identified seven second-order themes, which were on a higher level of abstraction compared to the first-order categories. In accordance with validity claims in the literature, the themes were further refined based on reviewer comments, insights from prior literature, and data from interviews and secondary sources such as internal documents, presentations, and newspapers [58]. This step was conducted conjointly by the researchers, facilitated by comprehensive discussions. Internal validity tests were conducted to ensure greater accuracy within the emergent themes. This was achieved through correspondence and follow-up discussions with selected informants. 
The third step involved the generation of aggregate dimensions that represented an even higher level of abstraction in the coding. The aggregate dimensions thus generated were built on the first-order categories and second-order themes to present a theoretically and practically grounded categorization. From the data, we constructed two aggregate dimensions around which our findings revolve: challenges in procurement of digital solutions (section 4.1) and Procurement 4.0 process for digital servitization (section 4.2). The data structure resulting from the data analysis process is presented in Figure 1.

As a final step, we engaged in theorizing the logic and linkages across aggregate dimensions, second-order themes, and first-order categories. Our aim was to synthetize the findings into a framework showing how the procurement of digital solutions unfolds and how firms manage the process (See Figure 2). 

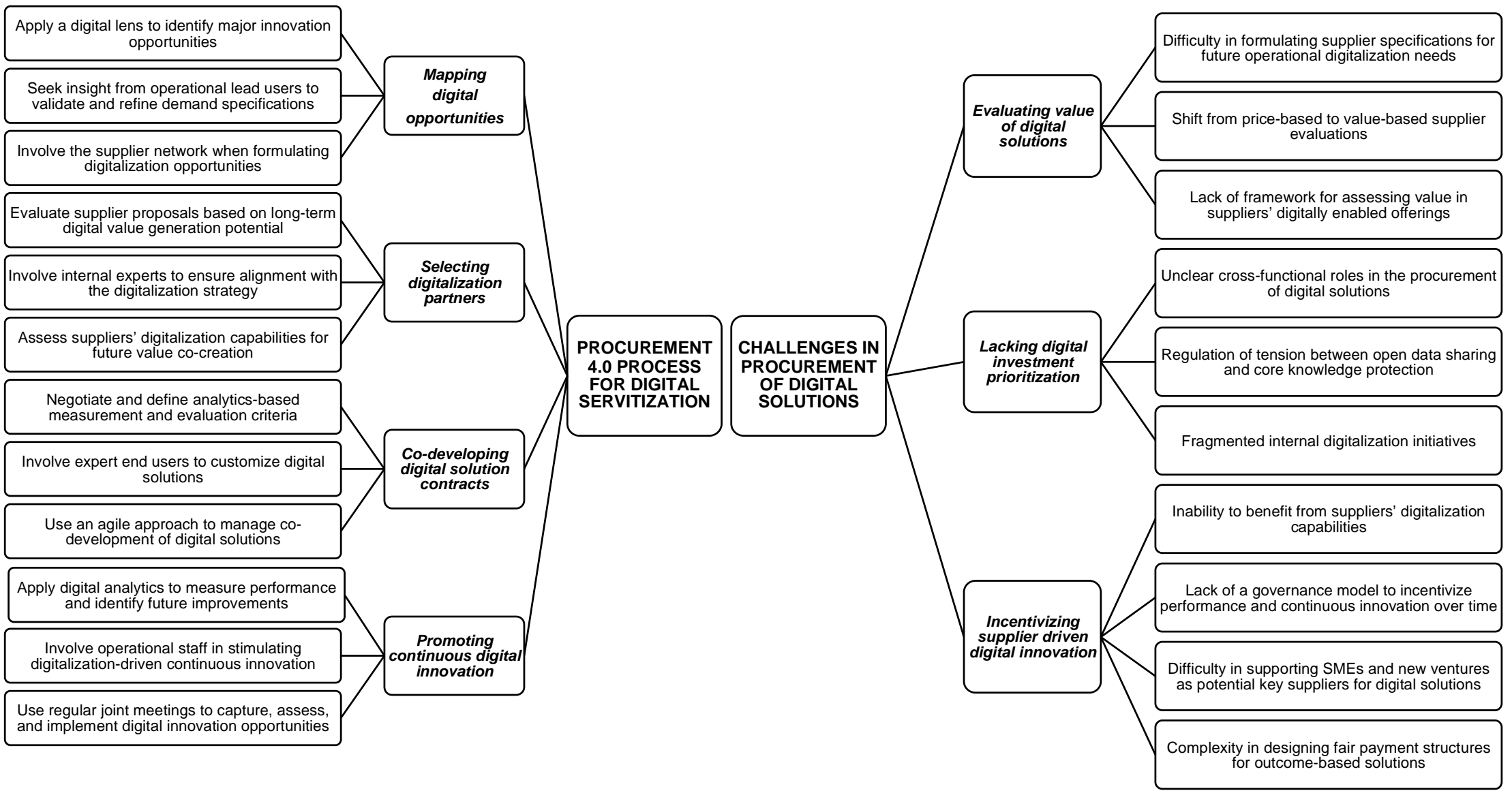

Figure 1. Data structure and coding process 


\section{Findings}

We sought to understand how a next-generation Procurement 4.0 process for digital servitization can be organized for industrial customers. We first identified the challenges the traditional procurement approach faced with digital servitization and then mapped how companies coped by revising their procurement processes. The following sections present the identified challenges in the procurement of digital services (4.1) and outline a next-generation procurement process for digital servitization (4.2).

\subsection{Challenges in procurement of digital solutions}

Procuring digital solutions, such as site optimization services and autonomous solutions, is a novel way of doing business for industrial companies. However, the novelty of the offering makes it an uncertain and challenging endeavor for the customer to fully understand the best way to buy such an offering. Therefore, identifying and understanding the challenges that are likely to arise in the procurement process is a crucial first step for successful implementation of Procurement 4.0 practices. Based on detailed analysis, we have identified three overarching challenges, which create obstacles and add complexity to the customer's organization when seeking to successfully procure digital solutions from progressive suppliers. Informants highlighted the need to develop and implement revised procurement processes to manage the new logic of digitalization.

\subsubsection{Evaluating value of digital solutions}

We find that a key challenge for industrial customers is to assess the value of digital services and solutions throughout the procurement process. This can be explained by the intangible nature of digital solutions and the uncertainty in procuring novel types of offering that are unfamiliar to the organization. Indeed, several informants from customer organizations recognized the difficulty in formulating supplier specifications for future operational digitalization needs. On the ongoing 
process of digital transformation, informants remarked that knowing how to specify the digital solutions needed now and in the future is a key challenge because both the technology and internal needs are rapidly evolving. This challenge is aggravated by the fact that many firms' procurement departments are not digitally savvy and are unfamiliar with, for example, digital business models such as site optimization services. For example, a procurement Manager from Zinkcorp remarked:

"This is a huge challenge to know what we want because the technology and our internal knowledge are evolving so rapidly. I find we are often one step behind, and it is difficult to choose a supplier then."

This challenge is further amplified by the need to move away from the well-known price-based supplier evaluation to the value-based alternative. Since many digital solutions are not comparable, the price point becomes less valid and may actually constrain digital innovation. However, valuebased discussions create challenges for which many procurement organizations are ill-prepared in their standard practice. A key account manager from Solutioncorp (supplier) described the challenge presented by this approach:

"Procurement organization tends to mainly look at the price differences and the detailing of contract obligations. They don't care about the value of the product or the service that we deliver, so it affects digital service negotiations in a bad way."

Procurement organization lacks an established framework for the assessment of value in suppliers' digitally enabled offerings. Digital solutions can involve running subscriptions or valuebased cost over time with contingencies. This approach adds to the uncertainty and complexity faced by the customer organization and usually results in the rejection of innovative digital solutions. A R\&D Manager from Ironcorp described this challenge:

"I think we are used to buying machines with a high capital expenditure, and then we get a service support agreement for three years. I know suppliers want to discuss other business 
models where they take more responsibility, but this does not align with how we make investments in projects, and frankly we don't know how to evaluate this."

\subsubsection{Lacking digital investment prioritization across organizational silos}

A second major challenge for industrial customers is the lack of investment prioritization across organizational silos. The procurement organization is faced with the need to coordinate crossfunctional roles concerning the purchase of digital solutions. This is because the procurement of digital solutions is not the sole responsibility of the procurement department; cross-functional inputs are required. Yet, the customer organization often lacks internal alignment in key functions such as procurement, $R \& D$, and operations. This misalignment can lead to internal pressures and missed opportunities. For example, many suppliers complained that misalignment between the procurement and operations departments could prevent deals for advanced digital solutions being closed, which had been co-developed with operational end users. For example, a R\&D Manager from Minceorp remarked:

"The role of the procurement function is changing. They need to take a more leading role toward coordinating needs from other functions. This means they are actively working with $R \& D$ and operational functions and jointly defining the solution requirements."

As digital solutions represent an entirely new form of offering, procurement organization often needs to find ways to enable data sharing, while ensuring that the organization's core knowledge is protected. This creates a tense and challenging arrangement between the procurement department and other functions including suppliers. A director of mine automation at Minecorp explained:

"As we see it, we own the data and, of course, the supplier does not like to see it this way... If we share our data, it is sensitive information which can impact our stock, but, on the other hand, if we don't, we can't rely on suppliers to digitalize. Without integrated data sets, the value is quite low." 
Finally, we found that responsibility to integrate digitalization within the work approach was often fragmented. Each unit had its own interpretation of how it should work to gain from digitalization. This considerable variation in perceived needs within the organization creates a major challenge for procurement activities. An operations manager from Truckcorp described this challenge:

“Everyone is working in their own different corner in digitalization ... and I can't see how it can benefit us if it's this fragmented."

\subsubsection{Incentivizing supplier driven digital innovation}

The final challenge relates to incentivizing supplier-driven digital innovation. We often found that the procurement department understood the need to gain from the supplier's digitalization capabilities but often failed in this pursuit. Leading suppliers have a much larger R\&D budget to drive digital innovation. Therefore, customers must consider how they can best use suppliers' knowledge and skills. Traditional procurement logics pay little attention to co-creation with suppliers, yet many informants remarked that close relationships with suppliers were becoming increasingly important for digital transformation. A project leader from Energycorp explained its importance in these words:

"What we have historically done is to buy a finished product with a service agreement but, in this case [of digitalization], it is impossible to do that... We need to do it together with someone; we can never do it ourselves."

An added challenge is that digital solutions are not one-time purchase offerings; they often require close cooperation between customer and supplier throughout the life of the contract and beyond to realize value and bring about improvement. But existing procurement activities lack the governance model to incentivize performance and continuous innovation over time. A procurement 
manager from Minecorp identified the uncertainty in trying to incentivize supplier performance over time:

"I have a feeling that over time the supplier performance will slip; it always tends to do. I think it is difficult to keep them on their toes without clear incentives for performance. This is a key risk we need to consider."

Another challenge with integrating suppler-driven innovation as a part of a new procurement strategy was to identify and nurture SMEs and new ventures as potential key suppliers of digital solutions. These actors lacked the financial and industrial expertise despite possessing a high level of digital competence that was viewed positively but was considered difficult to procure. A procurement manager from Minecorp explained:

"Mining is a very traditional industry, and for new smaller companies to become leading suppliers is challenging. But with digitalization, we see that we can't only rely on large product-centric players; we need fast-moving SME suppliers as well.”

Finally, how to design fair payment structures for advanced digital services with performance guarantees was recognized as a problem if aligned incentives were to be assured. For example, an IT manager from Ironcorp expressed the difficulty:

"We have been working with performance-based contracts for a while, but transforming performance into concrete value for us is not so easy... What really is the added value, this can be hard to define."

\subsection{Procurement 4.0 process for digital servitization}

Our informants indicated that industrial companies are often able to adapt the way they procure digital servitization offerings. It is clear that the standard procurement process for simple products or services seems not to work for digital solutions. Thus, the traditional procurement process of 
assignment specification followed by supplier selection, contract negotiation and development, and contract implementation [24] needs to be revised. Although few companies have formal processes for procuring digital solutions, helpful patterns of successful procurement practices would nevertheless seem to be in evidence. We mapped these activities to propose a next-generation procurement process (Procurement 4.0). Our suggested process has four phases: 1) mapping digital opportunities, 2) selecting digitalization partners, 3) co-developing solution contracts, and 4) promoting continuous innovation. Each phase has key activities and raises important questions. In the following sections, we detail each phase and its activities, providing examples from the case companies.

\subsubsection{Phase 1-Mapping digital opportunities}

Digitalization presents countless opportunities for operational improvements. For customers, the motivation for procuring digital innovations is the recognition of a particular need or the identification of a specific problem to be solved. The key question in this phase is: How can digitalization improve our business? However, selecting the right focus is difficult because of the speed of change. Consequently, we found that successful companies mapped digital opportunities in order to address key operational needs or problems.

The results show that it is helpful to apply a digital lens to identify major process innovation opportunities when defining requirements. A key is leveraging digital infrastructure and large-scale operational data collection to identify potential problem areas. For example, analyzing operational data from smart connected machinery can provide insights into opportunities for innovation and improvement. Accordingly, the requirements for innovation should be focused on filling a gap based on the analysis of facts and information. For instance, data analytics can help with the recognition and removal of bottlenecks. A common theme among operations managers was the 
vision of connecting equipment, installing sensors, collecting data, and analyzing these data more effectively to identify improvement opportunities that could involve the ecosystem of suppliers. An operations manager at Autocorp expanded on this theme when discussing a supplier's offerings:

"I think there is lot of technology now that makes it quite easy to connect sensors and to get data from our operational processes .... Actually, the issue now is how we should get some value from all this data that we are able to capture."

In selecting which digital opportunities to focus on, the procurement department should seek insights from operational lead users to validate and refine demand specifications. The operations department is responsible for the day-to-day work, so operations employees are best qualified to define the problem and specify what the needs are. This process should cover all kinds of requirements, including operational efficiency, safety, quality, and performance. A procurement manager at Minecorp explained what was needed:

"Of course, we create the overall blueprint, but [operations] need to create the specifications... because we are not experts... this is the key: to involve the stakeholders early.”

For example, in Transportcorp, the purchase of an Internet-of-Things platform directed at passengers involved drivers at an early stage. This involvement then led on to a critical feature being added to improve the security of Transportcorp's drivers.

Sometimes, focusing excessively on internal needs can be misguided in a context of fast-paced industry digitalization. All organizations struggle to stay abreast of emerging opportunities, so a helpful practice that informants suggested was to involve the ecosystem of suppliers when formulating digitalization opportunities. Discussing various options and possible solutions with suppliers can help a company brainstorm requirements and reflect on how best to tailor digital solutions to the company's specific needs. This process is especially helpful when repeated with 
diverse suppliers to obtain alternative perspectives. As a procurement manager at Minecorp reasoned:

"It's something that we do together in the end; even though the best ideas are coming from the supplier, it's not often that it fits directly into our needs or our process or whatever, so it needs to have interactive feedback back and forth."

The best ideas often come from combining customer knowledge of operational needs with supplier knowledge of technological solutions. For example, a supplier, Solutioncorp, recounted successful cases where customers had invited it to participate in creative sessions to identify potential process innovation opportunities from digital technologies. These opportunities then generated significant efficiency improvements, which led to the development of a completely new line of business for these customers.

\subsubsection{Phase 2 - Selecting digitalization partners}

Capitalizing on digitalization requires building an ecosystem of strong partnerships around the company. Once requirements and opportunities have been defined in the first phase, the purpose of the next phase is to find the best partner with whom to develop digital solutions. The key question is: Who can best help us digitalize and improve over time? This is a critical phase in evaluating supplier offerings_-identifying the "bells and whistles" (e.g., overly optimistic promises) and truly seeing what value and concrete benefit a supplier's offerings bring.

A key activity for the procurement department is to evaluate supplier proposals based on longterm digital value generation potential rather than immediate or short-term benefits. The decision of which supplier to select should be based on facts and current performance data as well as the future outlook for value expansion. The procurement department should select the supplier that can not only meet basic requirements but is also eager to continuously improve, to develop the 
capabilities for continuous innovation, and to demonstrate the financial strength to invest in digitalization to drive innovation. Thus, procurement must look beyond the current digital offerings of suppliers to consider their trajectory and potential for value accretion in the future. For example, informants in the mining industry were hesitant to partner with suppliers whose offerings are competitive today but who lag behind on critical investments in future autonomous and electrified machines and digital ecosystems. A program manager from Minecorp expressed this concern:

"It's critical that whichever investment we make is future proof for the next decade with regard to digitalization, Internet of Things, and sustainability."

To ensure adaptability, many informants recommended the use of modular and scalable digital platforms as an important evaluation criterion. A procurement manager at Minecorp stressed the importance of strategic and forward thinking, emphasizing that "the challenge is that, if you [want to] have a strategic partnership, it's to make them continuously improve." Minecorp decided not to select a particular supplier who, although a leader at the time, did not possess a mindset of openness and a commitment to continuous improvement of their digital offerings.

Evaluating the most competitive partner amongst suppliers is a challenge for the procurement department. To help with this decision, the selection process should involve internal experts who can ensure alignment with the digitalization strategy. Partner selection should be based on objective business criteria for digitalization, developed jointly by the procurement and operations teams so that goals are positively aligned. For example, Forestcorp had a key priority of reducing operational costs through digitalization. The key for the firm was to balance short-term cost reductions with developing long-term knowledge and digital capabilities to ensure continuous improvement and cost saving over time. This approach pushed supplier selection toward criteria such as the total cost of ownership rather than the purchase price. An operations manager at Forestcorp clarified the 
importance of aligning the approach with the digitalization strategy to ensure that resources are allocated wisely:

"We are making a lot of investments in our own digital system and, of course, to realize the benefits, we need to ensure that the supplier's contribution can be integrated in some form."

The procurement and operations departments should jointly assess suppliers' digitalization capabilities for future value co-creation. It is critical to assess the supplier's qualities in terms of customer-relationship management, the broader ecosystem of partners, and the necessary digitalization expertise. Supplier assessment may be based on the company's own experience or on the supplier's reputation in the marketplace. For example, Minecorp described how the decision to procure a new fleet of mine trucks had ultimately hinged on the supplier's openness and willingness to co-create value for the digital platform. A supplier's record of successful reference cases in co-creating customized digital solutions with customers can also offer a sound basis for cooperation. Powercorp cited the example of assessing suppliers' capabilities using a "tech-day" event arranged by one supplier. At this event, the end users of Powercorp and the procurement personnel directly interacted with the supplier, discussed opportunities, and evaluated the potential gains the supplier could bring to the company. This kind of professional interaction can determine the digital capabilities and co-creation skills that the supplier has to offer.

\subsubsection{Phase 3 - Co-developing digital solution contracts}

Digital solutions often entail a new supplier business model that requires careful attention from both sides to fully understand the implications for the business relationship. After the supplier has been selected, the details of the contract are negotiated between the customer and the supplier. The aim is to reach mutual agreement on feasible solutions, terms, conditions, and roles, and to establish the basis for the partnership in terms of guidelines and ways to jointly solve problems. The key question in this phase is: How can we create profitable solutions for both partners? A major 
concern is to ensure that the contract is flexible enough to adapt to change. Accordingly, the contract should allow for the incorporation of new priorities and opportunities that may arise in the future and potentially create greater value from digitalization.

The contract should also define how success is to be measured in order to evaluate supplier performance during implementation. Evaluating success, however, would not be possible without the necessary facts and data. Consequently, there is a need to negotiate and define analytics-based measurement and evaluation criteria. Such criteria facilitate a data-driven evaluation of performance during contract implementation and may be used to incentivize suppliers to focus on customer outcomes. Indeed, well-designed data analytics enable continuous improvement and promote ideas for further digital innovation. A procurement manager at Zinkcorp reiterated this point:

"We are increasingly focusing on setting up contracts that incentivize the supplier to use insights from data and analytics to continuously support us in improving our processes."

Hence, the parties should agree on how data are collected, analyzed, and used for improvements. For example, the installation of load-weighing solutions in trucks provides vital inputs on how many tons have been transported and whether the solution has achieved the agreed performance. A key element in such a solution is that both supplier and customer are actively engaged in using the collected data to optimize operations by identifying bottlenecks and issues that can be addressed over the life of the contract.

Again, it is critical to involve expert end users to customize digital solutions because these users have the know-how on operations and associated risks. Involving expert users helps address all relevant issues in the contract and develop a better idea of how to align the various operational processes and roles between firms. A procurement manager at Minecorp explained why contributions by knowledgeable end users are so important in this phase: 
"When you start negotiating, you must have done your homework in advance, so you understand what you are buying."

This sentiment highlights the importance of involving end users and internal customers in contract customization. For example, when Minecorp negotiated a contract for a new digital solution with a supplier, skilled and experienced people were deployed working on-site in the mines. Consequently, before the contract was signed, mine operations staff tested the technology, gave technical feedback to the supplier, and documented expectations that would help the digital solution succeed.

One useful practice is to develop agility in managing the customization and co-development of digital solutions. An agile approach involves embracing change through constant iteration and refinement of digital solutions, based on inputs from various firm actors. This is especially important in the contract co-development phase. Informants suggested that co-development should use a value-driven approach that embraces change, even if late in the solution development stage. A business development manager at Energycorp stressed the value of this approach:

"I think the open approach between us focusing on identifying what value we can create and defining the solutions together has been very helpful."

For example, when developing a digital platform, employees from Equipmentcorp explained that they had used an agile approach to manage the project with their customers. Initially, certain functionalities had been included in the platform but Equipmentcorp continued to develop them in cooperation with the customer, opening up new opportunities for improvement. This agile approach is worth enforcing by the customer when co-developing a solution with the partner.

\subsubsection{Phase 4 - Promoting continuous digital innovation}

A common mistake is to focus excessively on the signing of the contract as a "done deal" and to underestimate the importance of paying due regard to the actual operation of the contract. In 
reality, once the solution contract is finalized and all details have been settled, implementation and real value generation can take place. The key question in this phase is: How can we ensure a profitable partnership throughout the contract? The implementation stage should be a learning experience in which both parties continue to evaluate and improve in order to leverage the rapidly expanding value of digitalization. Ideal contract implementation should be flexible enough to encourage and reward innovation, creating a win-win situation.

Continuous evaluation and improvement, however, can only be achieved with relevant data. Therefore, applying digital analytics to measure performance and identify future ecosystem potential is necessary. Smart, connected machinery and associated platforms for data analytics can greatly support contract managers in evaluating the supplier's implementation of the contract but may also help identify future ecosystem collaboration opportunities. For example, it is important to keep reviewing the key performance indicators (KPIs) and revising them when necessary to ensure continuous innovation and improvement. This may also uncover areas where additional suppliers or independents software vendors from the ecosystem could become involved to expand the value of digital solutions. More importantly, expanding the value of digital solutions over the long term should build on a generative logic where additional value could be unlocked by engaging with the broader ecosystem. For example, an IT manager at Zinkcorp spoke positively of the exponential value that could be unlocked through digital solution investments:

"We need to invest in these digital solutions and monitor the data for ongoing improvements of our processes. But, I think the true value is over time once we start to have larger data sets and can explore these more openly with AI and analytics. New partnerships between solution providers and additional partners can be involved to offer radical and unexpected areas for operational improvement." 
Pulpcorp gave the example of how data generated from Solutioncorp's motors combined with AI functionalities helped to optimize operations, ensuring that each motor was used and maintained optimally. These data insights could also be leveraged to optimize the performance of the equipment that the motor is running.

While the procurement department oversees the evaluation of contract implementation, the operations department handles the day-to-day, on-site monitoring and use of the digital solutions. Consequently, it is necessary to involve operational staff in stimulating continuous innovation driven by digitalization. This involvement should be based on daily reviews and assessments of contract implementation. An operations manager at Minecorp stressed the importance of feedback:

"We have some skilled people in the mine ... and they are very good at giving goodfeedback to suppliers."

The manager explained that the firm has a standard reporting procedure that encourages operations staff to continually report opportunities for improvement and innovation. The manager also confirmed that this process was increasingly important for digital systems that were not yet mature. Digital innovation ideas could then be discussed with the technology suppliers based on the operational experience of using existing technologies.

To ensure that ideas for improvement are not lost, it is important to use regular joint meetings to capture, assess, and implement digital innovation opportunities. This step involves establishing a formal process with the supplier at the managerial level to manage ideas for improvement and innovation. The process should follow a framework for selecting ideas to be implemented and for establishing priorities. A business development manager at Energycorp stressed the value of frequent meetings:

"We have regular meetings on the strategic level with our supplier to prioritize next steps and ensure we can derive more value out of digitalization." 
In other words, ideas that are considered "low-hanging fruit" can be identified. These ideas are relatively easy to implement and can quickly yield benefits for both parties. Employees of Solutioncorp mentioned the example of using the quarterly steering meeting with their customer, Minecorp, to drive improvement. For example, when Minecorp raised an issue with Solutioncorp about the throughput in a mine hoist, a study was jointly conducted to develop a digital solution that was implemented on a cost-plus basis. Solutioncorp also intimated that this process could be inverted, with the supplier identifying a bottleneck and proposing a solution.

\subsection{A Procurement 4.0 process model for industrial customers in digital servitization}

This section brings together our key findings to develop a process model for Procurement 4.0 (see Figure 2). The model describes the foundation of the process, detailing key phases, activities, and principles in Procurement 4.0 for digital servitization. In essence, the empirical results reveal how industrial customers can utilize a more agile and relational way of working with suppliers and extended ecosystems, focusing on value rather than cost so as to profit from digital servitization. This model also highlights the changes needed in the procurement function to orchestrate relationships among suppliers and internally within the organization (e.g., R\&D and operations). 


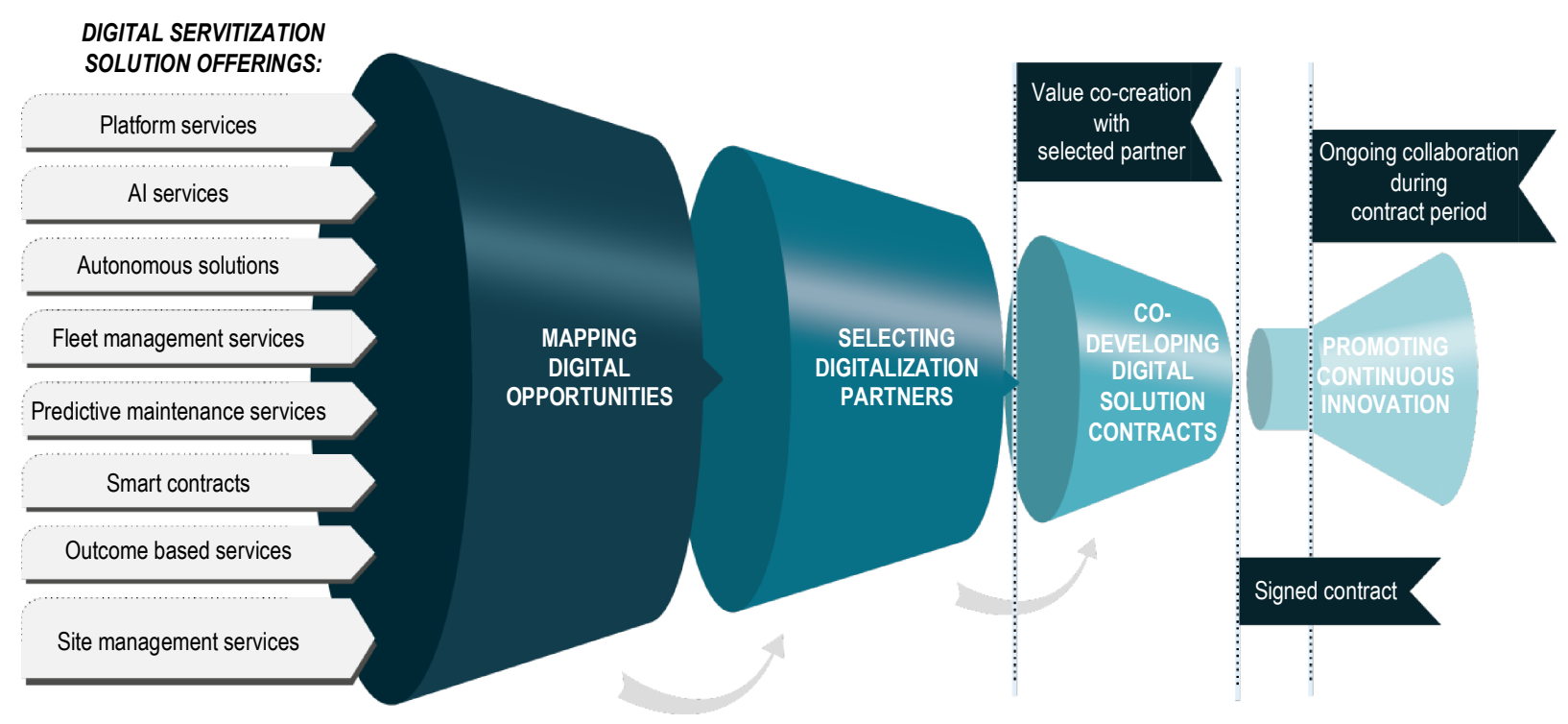

Figure 2. A Procurement 4.0 process model for industrial customers in digital servitization

Building on the structure of the standard procurement processes (e.g., [24]), we have revised the nature of phases and underlying activities to align with a digital servitization logic for Procurement 4.0. As presented in the previous section, the revised process model includes four key phases and corresponding logics: 1) mapping digital opportunities 2) selecting digitalization partners 3) co-developing digital solution contracts 4) promoting continuous digital innovation. However, our key insight is concerned with the customer procurement unit's need to reconfigure the underlining transactional principles into new Procurement 4.0 principles. Three overarching principles underpin the Procurement 4.0 approach and the corresponding activities that are required throughout the process: nurture digital ecosystem generativity, orchestrate cross-functional integration, and leverage supplier capabilities through agile co-creation. According to our respondents, these principles truly reflect the flexibility, pace, and ecosystem-relationship focus required for industrial customers to capitalize on digital servitization. Figure 3 presents an overview 
of the principles, phases, key questions, and key activities of the Procurement 4.0 process. Below, the principles are described in further detail.

\begin{tabular}{|c|c|c|c|c|}
\hline PHASES: & $\begin{array}{c}\text { MAPPING } \\
\text { DIGITAL } \\
\text { OPPORTUNITIES }\end{array}$ & $\begin{array}{l}\text { SELECTING } \\
\text { DIGITALIZATION } \\
\text { PARTNERS }\end{array}$ & $\begin{array}{l}\text { CO-DEVELOPING } \\
\text { DIGITAL SOLUTION } \\
\text { CONTRACTS }\end{array}$ & $\begin{array}{c}\text { PROMOTING } \\
\text { CONTINUOUS } \\
\text { DIGITAL INNOVATION }\end{array}$ \\
\hline KEY QUESTIONS: & $\begin{array}{c}\text { How can } \\
\text { digitalization improve } \\
\text { our business? }\end{array}$ & $\begin{array}{l}\text { Who can best help } \\
\text { us digitalize and } \\
\text { improve over time? }\end{array}$ & $\begin{array}{c}\text { How can we create } \\
\text { profitable solutions } \\
\text { for both partners? }\end{array}$ & $\begin{array}{c}\text { How can we ensure a } \\
\text { profitable partnership } \\
\text { over the contract? }\end{array}$ \\
\hline $\begin{array}{l}\text { Nurture digital } \\
\text { ecosystem } \\
\text { generativity }\end{array}$ & $\begin{array}{l}\text { Apply a digital lens } \\
\text { to identify major } \\
\text { process innovation } \\
\text { opportunities }\end{array}$ & $\begin{array}{l}\text { Evaluate supplier } \\
\text { proposals based } \\
\text { on long-term digital } \\
\text { value expansion } \\
\text { potential }\end{array}$ & $\begin{array}{l}\text { Define analytics- } \\
\text { based performance } \\
\text { criteria to incentivize } \\
\text { solution optimization }\end{array}$ & $\begin{array}{l}\text { Apply analytics to } \\
\text { measure performance } \\
\text { and identify future } \\
\text { ecosystem } \\
\text { collaboration }\end{array}$ \\
\hline $\begin{array}{l}\text { Orchestrate } \\
\text { cross-functional } \\
\text { integration }\end{array}$ & $\begin{array}{l}\text { Seek insight from } \\
\text { operational lead } \\
\text { users to validate } \\
\text { and refine demand } \\
\text { specifications }\end{array}$ & $\begin{array}{l}\text { Involve internal } \\
\text { experts to ensure } \\
\text { alignment with the } \\
\text { digitalization } \\
\text { strategy }\end{array}$ & $\begin{array}{l}\text { Involve expert end } \\
\text { users to customize } \\
\text { digital solutions }\end{array}$ & $\begin{array}{l}\text { Involve operational } \\
\text { staff in stimulating } \\
\text { digitalization-driven } \\
\text { continuous innovation }\end{array}$ \\
\hline $\begin{array}{c}\text { Leverage } \\
\text { supplier } \\
\text { capabilities } \\
\text { through agile co- } \\
\text { creation }\end{array}$ & $\begin{array}{l}\text { Involve the supplier } \\
\text { ecosystem when } \\
\text { formulating } \\
\text { digitalization } \\
\text { opportunities }\end{array}$ & $\begin{array}{l}\text { Assess suppliers' } \\
\text { digitalization } \\
\text { capabilities for } \\
\text { future value co- } \\
\text { creation }\end{array}$ & $\begin{array}{l}\text { Use an agile } \\
\text { approach to manage } \\
\text { co-development of } \\
\text { digital solutions }\end{array}$ & $\begin{array}{l}\text { Use regular joint } \\
\text { meetings to capture, } \\
\text { assess, and implement } \\
\text { digital innovation } \\
\text { opportunities }\end{array}$ \\
\hline
\end{tabular}

Figure 3. Principles, phases, and key activities of the Procurement 4.0 process

Nurture digital ecosystem generativity. Rapid digital technology advancements are set to change the way customers interact with and nurture their broader ecosystem of suppliers before, during, and after signing a contract. However, knowing where to start, which opportunities to exploit, and how to appropriately define the scope of the digital solutions are difficult issues. Hence, customers must use a digital lens to identify needs and opportunities, and they must monitor progress within their operations. Investing in a solid foundation of data and analytics of smart connected products provides enormous potential to improve performance by leveraging the ecosystem's capabilities for implementing novel digital solutions. However, adopting a progressive view on digitalization 
in procurement entails not only evaluating suppliers' existing solutions offerings but also identifying the future potential for value expansion through partnerships and continuous improvements. As more digital solutions are implemented within operations and comprehensive data sets become available, the scope for generativity increases. More specifically, firms may seek to adopt an open digital ecosystem of partners to allow other actors to add additional value and to expand solutions beyond the initial ideas that established the infrastructure and digital solutions.

Orchestrate cross-functional integration. While collaboration between suppliers and customers is required to source digital solutions, close cooperation between customers' internal actors is also critical. The goals and expectations of the procurement and the operations departments should be aligned. Here, clarity in the distribution of roles is vital. In contrast to procurement performing an administrative role, we recognize that procurement needs to coordinate with $R \& D$ to obtain novel technological insights, gather detailed requirements from the operational side, and acquire inputs on digital infrastructure from IT departments if digital service procurement is to be successful. Thus, in the digital age, the procurement department must become an orchestrator guiding the internal processes that clarify the roles and activities of each function during procurement.

Leverage supplier capabilities through agile co-creation. The entire process of procuring digital solutions should be based on the logic of co-creation between suppliers and customers. The vital question is how to combine knowledge and capabilities to jointly co-create value and achieve greater benefits for all. To ensure a win-win situation, communication at all levels, from both the managerial and operational perspectives, is required. The aim is to discuss new opportunities for improvement and innovation that will enhance value. For this, a flexible approach is required that allows for creativity and the opportunity to review how processes and operations should be carried out when new digitalization opportunities arise. 


\section{Conclusion}

By developing a Procurement 4.0 process model, the present study contributes to the emerging digital servitization literature, and offers managerial recommendations for senior managers in firms pursuing the procurement of digital solutions. The theoretical contributions and managerial recommendations are summarized in Table 3, followed by a more detailed discussion.

Table 3. A summary of the study's key theoretical contributions and managerial recommendations

\begin{tabular}{|l|l|}
\hline Theoretical contributions & \multicolumn{1}{c|}{ Managerial recommendations } \\
\hline $\begin{array}{l}\text { Conceptualizing an empirically grounded } \\
\text { Procurement 4.0 process model for digital servitization }\end{array}$ & $\begin{array}{c}\text { Seek to benefit from digital transparency through new } \\
\text { business models }\end{array}$ \\
$\begin{array}{l}\text { - Illustrating the central role of procurement as an } \\
\text { orchestrator of digital transformation and } \\
\text { collaboration internally and within ecosystems }\end{array}$ & $\begin{array}{c}\text { Ensure cross-fertilization and pollination within the } \\
\text { ecosystem }\end{array}$ \\
$\begin{array}{l}\text { - Advancing understanding of the challenges faced by } \\
\text { traditional procurement approaches in digital } \\
\text { servitization }\end{array}$ & $\begin{array}{l}\text { Automate recurring procurement processes and focus } \\
\text { resources on orchestrating strategic partnerships }\end{array}$ \\
\hline
\end{tabular}

\subsection{Theoretical contributions}

This study makes three theoretical contributions to the literature. First, we contribute by conceptualizing an empirically grounded Procurement 4.0 process model for digital servitization. Prior studies on servitization have presented several process models to co-create digital solutions from the supplier or supplier-customer perspective (e.g., [12], [15], [59]). However, no study has yet to investigate the opposing view of industrial customer procurement processes [6], [16]. Yet, there is a strong need to adapt the standard procurement models, which are not well suited to digital solutions [6]. Our model demonstrates that an alternative procurement approach is possible—one that is built on a co-creation logic with suppliers to enable quick, iterative refinement of specifications for digital solutions. The upshot is adaptability to changing requirements so that greater flexibility is injected into the procurement process. In line with this novel view, our study shows how industrial customers can develop a more digital mindset built on agility, innovation, 
and relational engagement in the digital solution procurement process. Despite its emphasis on the collaborative nature of value creation [5], [59]-[61], the literature provides scant detail on the joint activities, principles, and phases of value co-creation in digital servitization. The proposed Procurement 4.0 approach is built on three principles: nurture digital ecosystem generativity, orchestrate cross-functional integration, and leverage supplier capabilities through agile cocreation. These principles are implemented in the procurement process through an interactive approach over four phases. Accordingly, the value propositions made by the supplier are interactively aligned with the needs and requirements of the customer in developing digital solutions, and value capture is enabled for both parties [12]. We agree with Dey et al. [62] that digital technologies are not "a magic solution", and that there is a need for regular interactive dialogue between customers and suppliers for developing new technologies and altering existing ones to create value. Our findings show that, in the context of digital servitization, customers may need to exert considerable influence on the formulation of the value proposition by negotiating and contributing their own resources to the process of co-creation from an early stage.

Second, this study contributes by illustrating the central role of procurement as an orchestrator of digital transformation and collaboration internally and within ecosystems. Our model details how procurement directs interactions between key roles and activities across multiple organizational levels of both suppliers and customers to co-create value in digital servitization. Historically, research has focused on a more generalized and overarching level, whereas detailed explanations of such inter- and intra-organizational processes are less common [6], [12], [63]. We further emphasize how inter- and intra-organizational relationships impact value co-creation (e.g. [64]). More specifically, our findings indicate that procurement needs to involve different organizational functions that perform important roles and activities in each phase of the 
procurement process and that show the interlinkages with suppliers. Furthermore, we provide a detailed analysis of how such involvement changes as progress is made, from mapping opportunities and specifications to development of solution contracts, and ultimately to implementation of digital solutions. These findings contribute to the literature by providing empirically grounded conceptualizations of procurement's central task in orchestrating various roles involved in procuring digital solutions, whereas previous discussion has largely been confined to the overall relational level (e.g., [6]). In particular, we detail the important role of procurement in engaging the internal organization and the ecosystem in the pursuit of supplier-driven digitally enabled process innovation [10].

Third, this study contributes by advancing our understanding of the challenges faced by traditional procurement approaches in digital servitization. Indeed, industrial customers are increasingly being offered sophisticated digital solutions, but many companies still fail to adopt and manage such service contracts with the proficiency needed to create real value in their internal operations. Thus, the opportunities for increased value from digital solutions are squandered in practice because of a failure to surmount the challenges presented by the traditional procurement process. We identify and explain three overarching challenges: evaluating value of digital solutions, prioritizing digital investment across organizational silos, and incentivizing supplierdriven digital innovation. Failing to address these challenges can explain the failure on the part of both suppliers and customers to achieve a financial return on investment in the fast-changing digital world [12] and may point the way to the causes of value co-destruction and lower profits in digital servitization [65]. We further contend that addressing such challenges is a vital aspect of succeeding with digital transformation.

\subsection{Managerial implications}


A new procurement approach is needed to allow customers to fully benefit from digital servitization and to encourage continuous digital innovation by suppliers. Based on the challenges described in the background to this study and our proposed Procurement 4.0 process and principles, our findings can be summarized in three managerial recommendations.

First, seek to benefit from digital transparency through new business models. Greater operational transparency enables new forms of value creation. The traditional procurement model of procuring simple products and after-sales services is increasingly outdated. New business models built around digital technologies allow suppliers to contribute to real value generation by focusing on achieving customer outcomes. The complexity of digital solutions creates a need for customer organizations to view suppliers as strategic partners working side by side. The business model as operationalized in a contract should reflect that need.

Second, ensure cross-fertilization and pollination within the ecosystem. Innovation is becoming more open, and firms that can capitalize on this openness by building a fertile ecosystem around them stand to make immense gains. For example, by purchasing a digital platform from its supplier, Transportcorp has benefited from the fact that the platform is open to contributions from a world of application developers. In this case, the supplier was the driving force in nurturing the ecosystem, but some leading customers have taken a more proactive role to ensure innovation within their ecosystems. For example, Ironcorp recently launched a bid to build an innovation ecosystem for underground mining, inviting suppliers to join forces to solve operational challenges with the support of a specified amount of funding.

Finally, we recommend that procurement functions increasingly automate recurring processes and focus their resources on orchestrating strategic partnerships. Leading companies are learning to automate the standard transactional procurement of low-value or commoditized products and services by building digital capabilities to enhance efficiency and effectiveness. For example, 
automating simple tasks such as invoicing and recurring orders of consumables creates more time to develop insights from data and to use these insights to identify improvement opportunities. In consequence, attention can be focused on orchestrating strategic partnerships with suppliers that have the potential to generate key value through digital solutions.

\subsection{Limitations and future research directions}

This study relies on in-depth case studies of the procurement of digital solutions in complex industrial B2B settings, such as manufacturing and process industries. While our results are garnered in the specific context of digital servitization in $\mathrm{B} 2 \mathrm{~B}$, we posit that these findings are still highly relevant and have the power to inspire other sectors such as public procurement. Nevertheless, it is important to stress that the findings should be considered applicable primarily to industrial B2B contexts characterized by similar conditions. Although the empirical basis for our conclusions is rather broad, we appreciate that future work on procurement processes could test the boundary conditions of our framework, depending on types of industry, for example.

We believe that the current approach of studying next-generation procurement processes, building on digital servitization, provides a highly beneficial avenue for further research. The current study has only begun to scratch the surface of the roles and practices through which internal alignment for procurement of digital solutions is achieved. These may have important implications for subsequent steps in understanding digital transformation and data-driven organizations. An interesting line of inquiry is related to the role of the supply chain manager in this process. Whilst Lyal, Mercier, and Gstettner [66] reason that that digitalization will eventually lead to "the death of supply chain management", we argue that supply chain managers will still play key roles in the next-generation procurement process. We foresee that their role in strategically structuring the 
company's value chains and ecosystems besides managing strategic relationships with suppliers will remain vital. Therefore, we suggest that researchers engage in such academic debate.

Moreover, we suggest further research on the contract specifications between customers and suppliers regarding digital solutions and how these unfold as the relationships mature. Additionally, different types of digital solution business model (e.g. outcome, result, subscription) —and the conditions under which each is the most appropriate route to go down-merit further examination. For example, what are the benefits and tradeoffs of various business model configurations for industrial customers? In particular, examining the effects of such arrangements on multiple levels-relational, organizational, functional, and individual-would seem to be a fruitful line of inquiry.

Finally, we acknowledge that industrial procurement increasingly extends beyond dyadic relationships to involve multiple ecosystem actors who collaborate to allow a focal value proposition to materialize [5], [10]. Exploring the emergence of digital solutions through cocreation among different ecosystem actors (e.g., suppliers, service delivery partners, and customers) could provide interesting multi-actor perspectives for future procurement and digital servitization research. A more in-depth analysis of how these types of ecosystem relationship impact the procurement process would be highly illuminating-particularly, in emerging contexts such as autonomous solutions [67].

\section{References}

[1] J. Cenamor, D. Rönnberg Sjödin, and V. Parida, “Adopting a platform approach in servitization: Leveraging the value of digitalization,” Int. J. Prod. Econ., vol. 192, no. November 2016, pp. 54-65, 2017, doi: 10.1016/j.ijpe.2016.12.033.

[2] M. Iansiti and K. R. Lakhani, "Digital ubiquity: How connections, sensors, and data are revolutionizing 
business," Harv. Bus. Rev., no. November 2014, 2014, doi: 10.2469/dig.v45.n2.8.

[3] M. E. Porter and J. E. Heppelmann, "How smart, connected products are transforming companies," Harv. Bus. Rev., vol. 2015, no. October, 2015.

[4] S. Karadayi-Usta, "An Interpretive Structural Analysis for Industry 4.0 Adoption Challenges," IEEE Trans. Eng. Manag., vol. 67, no. 3, pp. 973-978, 2020, doi: 10.1109/TEM.2018.2890443.

[5] V. Parida, D. Sjödin, and W. Reim, "Reviewing literature on digitalization, business model innovation, and sustainable industry: Past achievements and future promises," Sustain., vol. 11, no. 2, 2019, doi: $10.3390 / \mathrm{su} 11020391$.

[6] A. Kamalaldin, L. Linde, D. Sjödin, and V. Parida, “Transforming provider-customer relationships in digital servitization: A relational view on digitalization,” Ind. Mark. Manag., vol. 89, no. November 2019, pp. 306325, 2020, doi: 10.1016/j.indmarman.2020.02.004.

[7] W. Coreynen, P. Matthyssens, and W. Van Bockhaven, "Boosting servitization through digitization: Pathways and dynamic resource configurations for manufacturers," Ind. Mark. Manag., vol. 60, pp. 42-53, 2017, doi: 10.1016/j.indmarman.2016.04.012.

[8] D. R. Sjödin, V. Parida, M. Leksell, and A. Petrovic, "Smart Factory Implementation and Process Innovation: A Preliminary Maturity Model for Leveraging Digitalization in ManufacturingMoving to smart factories presents specific challenges that can be addressed through a structured approach focused on people, p,” Res. Technol. Manag., vol. 61, no. 5, pp. 22-31, 2018, doi: 10.1080/08956308.2018.1471277.

[9] S. K. Milewski, K. J. Fernandes, and M. P. Mount, "Exploring technological process innovation from a lifecycle perspective," Int. J. Oper. Prod. Manag., vol. 35, no. 9, pp. 1312-1331, 2015, doi: 10.1108/IJOPM02-2015-0105.

[10] A. Kamalaldin, D. Sjödin, D. Hullova, and V. Parida, "Configuring ecosystem strategies for digitally enabled process innovation: A framework for equipment suppliers in the process industries," Technovation, no. February, 2021, doi: 10.1016/j.technovation.2021.102250.

[11] L. Linde, D. Sjödin, V. Parida, and J. Wincent, "Dynamic capabilities for ecosystem orchestration A capability-based framework for smart city innovation initiatives," Technol. Forecast. Soc. Change, vol. 166, 2021, doi: 10.1016/j.techfore.2021.120614.

[12] D. Sjödin, V. Parida, M. Kohtamäki, and J. Wincent, "An agile co-creation process for digital servitization: 
A micro-service innovation approach,” J. Bus. Res., 2020.

[13] M. Kohtamäki, V. Parida, P. Oghazi, H. Gebauer, and T. Baines, "Digital servitization business models in ecosystems: A theory of the firm,” J. Bus. Res., vol. 104, no. May, pp. 380-392, 2019, doi: 10.1016/j.jbusres.2019.06.027.

[14] A. Ziaee Bigdeli et al., "Measuring servitization progress and outcome: the case of 'advanced services,", Prod. Plan. Control, vol. 29, no. 4, pp. 315-332, 2018, doi: 10.1080/09537287.2018.1429029.

[15] D. Sjödin, V. Parida, M. Palmié, and J. Wincent, "How AI capabilities enable business model innovation: Scaling AI through co-evolutionary processes and feedback loops,” J. Bus. Res., vol. 134, no. June, pp. 574587, 2021, doi: 10.1016/j.jbusres.2021.05.009.

[16] D. Rönnberg Sjödin, V. Parida, and J. Lindström, "Barriers and conditions of open operation: A customer perspective on value co-creation for integrated product-service solutions," Int. J. Technol. Mark., vol. 12, no. 1, pp. 90-111, 2017, doi: 10.1504/IJTMKT.2017.081505.

[17] V. M. Story, C. Raddats, J. Burton, J. Zolkiewski, and T. Baines, "Capabilities for advanced services: A multi-actor perspective,” Ind. Mark. Manag., vol. 60, pp. 54-68, 2017, doi:

10.1016/j.indmarman.2016.04.015.

[18] F. Nordin, "Linkages between service sourcing decisions and competitive advantage: A review, propositions, and illustrating cases," Int. J. Prod. Econ., vol. 114, no. 1, pp. 40-55, 2008, doi: 10.1016/j.ijpe.2007.09.007.

[19] R. Geissbauer, R. Weissbarth, and J. Wetzstein, “Are you ready for the digital revolution?,” $P w c$, no. 1, p. $12,2016$.

[20] J. Hughes and D. Ertel, "The reinvention of procurement," Supply Chain Manag. Rev., pp. 18-23, 2016.

[21] A. Abidi, F. Russo, M. Sommerer, and A. Streif, "Digital procurement: For lasting value, go broad and deep," McKinsey, no. November, 2018.

[22] D. Sjödin, V. Parida, and M. Kohtamäki, "Relational governance strategies for advanced service provision: Multiple paths to superior financial performance in servitization,” J. Bus. Res., vol. 101, no. March, pp. 906915, 2019, doi: 10.1016/j.jbusres.2019.02.042.

[23] V. Parida, D. R. Sjödin, J. Wincent, and M. Kohtamäki, "Mastering the transition to product-service provision: Insights into business models, Learning activities, and capabilities," Res. Technol. Manag., vol. 57, no. 3, pp. 44-52, 2014, doi: 10.5437/08956308X5703227. 
[24] A. J. Van Weele, Purchasing and Supply Chain Management: Analysis, Strategy, Planning and Practice, 4th ed. London: Thomson Learning, 2005.

[25] A. H. Glas and F. C. Kleemann, “The Impact of Industry 4 . 0 on Procurement and Supply Management: A Conceptual and Qualitative Analysis,” Int. J. Bus. Manag. Invent., vol. 5, no. 6, pp. 55-66, 2016.

[26] D. R. Sjödin and P. E. Eriksson, "Procurement procedures for supplier integration and open innovation in mature industries," Int. J. Innov. Manag., vol. 14, no. 4, pp. 655-682, 2010, doi: $10.1142 / \mathrm{S} 1363919610002817$.

[27] H. Gebauer et al., "How to convert digital offerings into revenue enhancement - Conceptualizing business model dynamics through explorative case studies," Ind. Mark. Manag., vol. 91, no. October, pp. 429-441, 2020, doi: 10.1016/j.indmarman.2020.10.006.

[28] J. Pearson and K. Gritzmacher, "Integrating Purchasing into Strategic Management”, Long Range Planning," Long Range Plann., vol. 23, no. 3, pp. 91-99, 1990.

[29] R. E. Spekman, J. W. Kamauff, and D. J. Salmond, “At last purchasing is becoming strategic,” Long Range Plann., vol. 27, no. 2, pp. 76-84, 1994, doi: 10.1016/0024-6301(94)90211-9.

[30] A. Tunisini and R. Sebastiani, "Innovative and networked business functions: Customer-driven procurement," J. Bus. Ind. Mark., vol. 30, no. 3-4, pp. 302-311, 2015, doi: 10.1108/JBIM-06-2014-0118.

[31] M. Day, "Gower handbook of purchasing management," Gower Publishing Ltd., 2002.

[32] T. Y. Choi, Z. Wu, L. Ellram, and B. R. Koka, "Supplier - Supplier Relationships and Their Implications for Buyer - Supplier Relationships,” IEEE Trans. Eng. Manag., vol. 49, no. 2, pp. 119-130, 2002.

[33] L. C. Giunipero and R. R. Brand, "Purchasing's Role in Supply Chain Management," The International Journal of Logistics Management, vol. 7, no. 1. pp. 29-38, 1996, doi: 10.1108/09574099610805412.

[34] B. Axelsson and J. Y. F. Wynstra, Buying business services. Wiley, 2002.

[35] N. Lindberg and F. Nordin, "From products to services and back again: Towards a new service procurement logic,” Ind. Mark. Manag., vol. 37, no. 3, pp. 292-300, 2008, doi: 10.1016/j.indmarman.2007.07.006.

[36] W. J. Wittreich, “How to Buy/Sell Professional Services,” Harv. Bus. Rev., 1966.

[37] F. Bienhaus and A. Haddud, "Procurement 4.0: factors influencing the digitisation of procurement and supply chains," Bus. Process Manag. J., vol. 24, no. 4, pp. 965-984, 2018, doi: 10.1108/BPMJ-06-20170139. 
[38] F. Wu, G. A. Zsidisin, and A. D. Ross, “Antecedents and outcomes of E-procurement adoption: An integrative model," IEEE Trans. Eng. Manag., vol. 54, no. 3, pp. 576-587, 2007, doi: 10.1109/TEM.2007.900786.

[39] P. Trkman and K. McCormack, "Estimating the benefits and risks of implementing E-procurement," IEEE Trans. Eng. Manag., vol. 57, no. 2, pp. 338-349, 2010, doi: 10.1109/TEM.2009.2033046.

[40] S. Hoejmose, S. Brammer, and A. Millington, "An empirical examination of the relationship between business strategy and socially responsible supply chain management," Int. J. Oper. Prod. Manag., vol. 33, no. 5, pp. 589-621, 2013, doi: 10.1108/01443571311322733.

[41] L. Linde, J. Frishammar, and V. Parida, "Revenue Models for Digital Servitization: A Value Capture Framework for Designing, Developing, and Scaling Digital Services,” IEEE Trans. Eng. Manag., pp. 1-16, 2021, doi: 10.1109/tem.2021.3053386.

[42] M. Kohtamäki, V. Parida, P. C. Patel, and H. Gebauer, "The relationship between digitalization and servitization: The role of servitization in capturing the financial potential of digitalization," Technol. Forecast. Soc. Change, vol. 151, no. November 2019, 2020, doi: 10.1016/j.techfore.2019.119804.

[43] W. Reim, D. Sjödin, and V. Parida, "Mitigating adverse customer behaviour for product-service system provision: An agency theory perspective," Ind. Mark. Manag., vol. 74, no. August, pp. 150-161, 2018, doi: 10.1016/j.indmarman.2018.04.004.

[44] R. K. Yin, Case study research and applications: Design and methods. Sage, 2018.

[45] K. M. Eisenhardt and M. E. Graebner, "Theory Building from Cases: Opportunities and Challenges," Acad. Manag. J., vol. 50, no. 1, pp. 25-32, 2007, doi: 10.1002/job.

[46] D. A. Gioia, K. G. Corley, and A. L. Hamilton, "Seeking Qualitative Rigor in Inductive Research: Notes on the Gioia Methodology," Organ. Res. Methods, vol. 16, no. 1, pp. 15-31, 2013, doi:

$$
10.1177 / 1094428112452151 .
$$

[47] A. C. Edmondson and S. E. Mcmanus, "Methodological fit in management field research," Acad. Manag. Rev., vol. 32, no. 4, pp. 1155-1179, 2007, doi: 10.5465/AMR.2007.26586086.

[48] K. R. Tuli, A. K. Kohli, and S. G. Bharadwaj, "Rethinking Customer Solutions: From Product Bundles to Relational Processes,” J. Mark., vol. 71, no. 3, pp. 1-17, 2007, doi: 10.1509/jmkg.71.3.1.

[49] H. W. Chesbrough, W. Vanhaverbeke, and J. West, Open innovation: Researching a new paradigm. Oxford, 
UK: Oxford University Press, 2006.

[50] K. M. Eisenhardt, "Building Theories from Case Study Research,” Acad. Manag. Rev., vol. 14, no. 4, pp. 532-550, 1989, doi: 10.1016/s0140-6736(16)30010-1.

[51] D. Leonard-Barton, “A Dual Methodology for Case Studies: Synergistic Use of a Longitudinal Single Site with Replicated Multiple Sites,” Organ. Sci., vol. 1, no. 3, pp. 248-266, Aug. 1990, doi: 10.1287/orsc.1.3.248.

[52] J. Grönlund, D. R. Sjödin, and J. Frishammar, "Open Innovation and the Stage-Gate Process: A Revised Model for New Product Development," Calif. Manage. Rev., vol. 52, no. 3, pp. 106-131, 2010, doi: 10.1525/cmr.2010.52.3.106.

[53] T. D. Jick, "Mixing Qualitative and Quantitative Methods: Triangulation in Action,” Adm. Sci. Q., 1979, doi: 10.2307/2392366.

[54] V. Braun and V. Clarke, "Using thematic analysis in psychology," Qual. Res. Psychol., vol. 3, no. 2, pp. 77101, 2006, doi: 10.1191/1478088706qp063oa.

[55] A. Strauss and J. Corbin, Basics of Qualitative Research. Thousand Oaks, CA: Sage, 2015.

[56] S. M. Ben-Menahem, G. Von Krogh, Z. Erden, and A. Schneider, "Coordinating knowledge creation in multidisciplinary teams: Evidence from early-stage drug discovery,” in Academy of Management Journal, 2016, vol. 59, no. 4, pp. 1308-1338, doi: 10.5465/amj.2013.1214.

[57] D. Sjödin, J. Frishammar, and S. Thorgren, "How Individuals Engage in the Absorption of New External Knowledge: A Process Model of Absorptive Capacity,” J. Prod. Innov. Manag., vol. 36, no. 3, pp. 356-380, May 2019, doi: 10.1111/jpim.12482.

[58] N. Kumar, L. W. Stern, and J. C. Anderson, “Conducting Interorganizational Research Using Key Informants,” Acad. Manag. J., vol. 36, no. 6, pp. 1633-1651, 1993, doi: 10.2307/256824.

[59] D. Rönnberg Sjödin, V. Parida, and J. Wincent, "Value co-creation process of integrated product-services: Effect of role ambiguities and relational coping strategies," Ind. Mark. Manag., Apr. 2016, doi: 10.1016/j.indmarman.2016.03.013.

[60] C. Grönroos, “A service perspective on business relationships: The value creation, interaction and marketing interface," Ind. Mark. Manag., vol. 40, no. 2, pp. 240-247, 2011, doi: 10.1016/j.indmarman.2010.06.036.

[61] S. L. Vargo and R. F. Lusch, "Service-dominant logic: Continuing the evolution," J. Acad. Mark. Sci., vol. 
36, no. 1, pp. 1-10, 2008, doi: 10.1007/s11747-007-0069-6.

[62] B. L. Dey, M. M. Babu, M. Rahman, M. Dora, and N. Mishra, "Technology upgrading through co-creation of value in developing societies: Analysis of the mobile telephone industry in Bangladesh," Technol. Forecast. Soc. Change, vol. 145, no. May 2018, pp. 413-425, 2019, doi: 10.1016/j.techfore.2018.05.011.

[63] L. Aarikka-Stenroos and E. Jaakkola, "Value co-creation in knowledge intensive business services: A dyadic perspective on the joint problem solving process," Ind. Mark. Manag., vol. 41, no. 1, pp. 15-26, 2012, doi: 10.1016/j.indmarman.2011.11.008.

[64] M. He, T. Wang, H. Xia, and J. Dai, "Empirical research on how social capital influence inter-organizational information systems value co-creation in China," Asia Pacific Bus. Rev., vol. 00, no. 00, pp. 1-25, 2021, doi: $10.1080 / 13602381.2021 .1889124$.

[65] P. Echeverri and P. Skålén, "Co-creation and co-destruction: A practice-theory based study of interactive value formation," Mark. Theory, vol. 11, no. 3, pp. 351-373, 2011, doi: 10.1177/1470593111408181.

[66] A. Lyall, P. Mercier, and S. Gstettner, "The Death of Supply Chain Management," Harv. Bus. Rev., vol. June $15,2018$.

[67] L. Thomson, A. Kamalaldin, D. Sjödin, and V. Parida, "A maturity framework for autonomous solutions in manufacturing firms: The interplay of technology, ecosystem, and business model," Int. Entrep. Manag. J., 2021, doi: 10.1007/s11365-020-00717-3. 